\title{
Sosialisasi Pemasangan, Pengoperasian Dan Pemeliharaan Panel Surya Fotovoltaik Di Pondok Pesantren Khoiru Ummah, Sumedang
}

\author{
Agus Yogianto $^{1}$; EddyIspranyoto ${ }^{2}$; Emilia $^{3} ;$ Sriyayi $^{4}$ \\ 1, 2, 3,4 Institut Teknologi PLN \\ 1 agus.yogianto@itpln.ac.id \\ 2 edy.ispranyoto@itpln.ac.id \\ 3 emillia@itpln.ac.id \\ ${ }^{4}$ sriyayi@itpln.ac.id
}

\begin{abstract}
The use of photovoltaic / PV panels as household scale power plants is still relatively limited in number, but is expected to increase in the future. Meanwhile the understanding of the operating technology of $P V$ solar panels in the community is still very limited, so that it can affect the optimization of the use and utilization of PV panels as power plants. Based on this, the Community Service Team / PkM of the PLN Technology Institute took the topic of the socialization of installation, operation and maintenance of solar panels as power plants to be delivered to PLN Technology Institute partners namely STP / SMP-SMA Khoiru Ummah Islamic Boarding School, Tanjung Sari District, Regency Sumedang, West Java. This socialization aims to ensure that participants consisting of students and teachers as part of Indonesian society can have the knowledge and practical skills related to the installation, operation and maintenance of PV panels and their equipment. The PkM activity begins with the planning, preparation of equipment, preparation of procedures / materials for the dissemination and realization of the implementation of the socialization. From the socialization that was carried out in early July 2020, it can be seen that the participants need this socialization. Based on the initial discussion and after the socialization, it can be seen that this PkM activity is useful to increase knowledge and understanding of renewable energy for electricity generation.
\end{abstract}

Keywords: solar panel, instalation, operation, maintenance

\begin{abstract}
Abstrak
Penggunaan panel fotovoltaik/PV sebagai pembangkit listrik skala rumah tangga relatif masih terbatas jumlahnya, tetapi diperkirakan akan semakin meningkat di masa mendatang. Sementara itu pemahaman terhadap teknologi pengoperasian panel surya PV di masyarakat masih sangat terbatas, sehingga dapat berpengaruh terhadap optimalisasi penggunaan dan pemanfaatan panel PV sebagai pembangkit listrik. Berdasarkan hal ini maka Tim Pengabdian kepada Masyarakat/PkM Institut Teknologi PLN mengambil topik yaitu sosialisasi pemasangan, pengoperasian dan pemeliharaan panel surya sebagai pembangkit listrik untuk disampaikan kepada mitra Institut Teknologi PLN yaitu STP/SMP-SMA Pondok Pesantren Khoiru Ummah, Kecamatan Tanjung Sari, Kabupaten Sumedang, Jawa Barat. Sosialiasasi ini bertujuan agar para peserta yang terdiri dari siswa dan pengajar sebagai bagian dari masyarakat Indonesia dapat memiliki pengetahuan dan ketrampilan praktis yang berkaitan dengan pemasangan, operasi, dan pemeliharaan panel PV serta perangkatnya. Kegiatan PkM diawali dengan perencanaan, persiapan perangkat, penyusunan prosedur/bahan sosialisasi dan realisasi pelaksanaan sosialisasi. Dari sosialisasi yang sudah dilaksanakan di awal Juli 2020, dapat diketahui bahwa para peserta membutuhkan sosialisasi ini. Berdasarkan diskusi awal dan setelah diberikan sosialisasi dapat diketahui bahwa kegiatan PkM ini bermanfaat untuk meningkatkan pengetahuan dan pemahaman terhadap energi terbarukan untuk pembangkitan tenaga listrik.
\end{abstract}

Kata kunci: panel surya, pemasangan, operasi, pemeliharaan 


\section{PENDAHULUAN}

Penggunaan modul / panel fotovoltaik ( $P V$ module) sebagai pembangkit tenaga listrik skala rumah sudah dimulai pada tahun-tahun terakhir ini di Indonesia, walaupun relatif belum banyak. Pada masa mendatang diperkirakan dengan semakin murahnya harga modul/panel serta aturan pemerintah yang mendukung digunakannya modul/panel PV, maka diperkirakan jumlah pemakai modul/panel PV akan semakin meningkat.

Persoalan pemanfaatan tenaga listrik dengan panel PV tidak hanya terkait panel PV, tetapi juga dengan perangkat lain yang diperlukan pada suatu sistem panel PV yaitu inverter, sarana indikator dan perangkat lain[1]. Bagi sebagian besar masyarakat, penggunaan PV dan perangkatnya masih merupakan hal yang baru, sehingga penanganan terhadap instalasi panel PV dan perangkatnya masih belum memadai, sehingga berakibat umur pemakaian atau masa manfaat dari panel PV dan perangkatnya tidak sesuai dengan rencana dari disainer atau pabrikan.

Adanya gap pengetahuan baik ilmu maupun hal praktis merupakan situasi permasalahan yang dihadapi masyarakat yang berminat pada pemanfaatan energi terbarukan yang saat ini mulai digunakan oleh sebagian masyarakat. Permasalahan ini ditanggapi oleh tim Pengabdian kepada Masyarakat (PkM) Institut Teknologi PLN sebagai kesempatan untuk melaksanakan pengabdian kepada masyarakat agar dapat meningkatkan diri dalam pengetahuan dan ketrampilan pada bidang energi terbarukan khususnya tenaga listrik dari energi surya dengan panel fotovoltaik.

Sementara itu dari mulai tahun 2016 sampai dengan tahun 2019, dari Kementrian ESDM, telah mengeluarkan berbagai peraturan yang pada dasarnya berusaha untuk memberikan dorongan atau daya tarik untuk semakin meningkatkan penggunaan energi terbarukan sebagai sumber tenaga listrik, sehingga porsi energi terbarukan dalam porsi penggunaan energi keseluruhan di Indonesia akan semakin meningkat di waktu mendatang[2]-[5].

Seperti masyarakat pada umumnya, penggunaan teknologi yang relatif baru ini merupakan hal yang tidak biasa bagi kehidupan masyarakat pada umumnya yang biasa memanfaatkan tenaga listrik dari pasokan listrik perusahaan utilitas/PLN[6]. Permasalahan kurangnya pemanfaatan, kurang terpelihara atau bahkan kerusakan dari instalasi biasa diawali dari kurang peduli serta kurangnya pemahaman terhadap instalasi modul/panel PV serta teknologi Modul/Panel PV[7].

Pemanfaatan tenaga listrik dari modul/panel PV menjadi suatu hal baru bagi sebagian besar masyarakat, demikian pula pada para penghuni pondok pesantren STP SMP/SMA Khoiru Ummah, Sumedang, permasalahan mulai dari belum mengenal panel surya fotovoltaik, pengoperasian, pemeliharaan serta pengetahuan tentang regulasi adalah masalah yang harus diselesaikan oleh tim PkM Institut Teknologi PLN. Oleh sebab itu tim PkM dalam kegiatan ini mengadakan sosialisasi dan pelatihan pemasangan dan pengoperasian panel PV serta pemeliharaannya.

\section{METODE}

Berdasarkan latar belakang tersebut maka untuk metode yang digunakan pada kegiatan program Pengabdian kepada Masyarakat ini dipilih metode gabungan yaitu penyuluhan dan peragaan. Untuk mewujutkan program tersebut maka disusun materi sebagai berikut :

1. Pemasangan panel PV dan perangkat

2. Pengoperasian dan pemeliharaan PV

3. Instalasi panel PV

4. Aturan / ketentuan PLTS atap. 


\subsection{Pemasangan, operasi dan pemeliharaan instalasi panel surya}

Pada persiapan pemasangan harus sudah dibuat dudukan modul atau support modul, hal ini berlaku untuk roof top atau untuk dipasang di permukaan tanah.

Instalasi panel PV adalah instalasi listrik, untuk instalasi permanen harus disiapkan grounding yang memenuhi ketentuan instalasi.

Posisi dudukan di permukaan tanah harus dipilih sedemikian rupa, sehingga posisi permukaan modul PV menghadap ke arah lintasan matahari. Bila posisi koordinat lokasi berada pada lintang selatan, maka posisi dudukan menghadap miring ke arah Utara, pula sebaliknya. Pastikan posisi dudukan dan modul tidak mengalami bayangan baik bayangan langsung maupun tidak langsung.

Periksa terminal modul yang terdiri dari 2 terminal yaitu terminal positif (+) dan terminal negatif (-). Posisi terminal ini biasa berada di belakang permukaan modul PV. Hal penting pada waktu pemasangan adalah berhati-hati terhadap tegangan listrik. Bagian terminal adalah bagian yang bertegangan ketika terjadi penyinaran matahari, oleh sebab itu perlu diperhatikan keamanan diri terkait bagian yang bertegangan. Kabel penghantar positif dan kabel penghantar negatif keluaran panel surya keduanya menuju suatu boks konektor tegangan searah yang dilengkapi kontak dan pengaman. Dari boks tersebut kabel penghantar tegangan positif menuju terminal positif masukan inverter dan kabel penghantar negatif menuju terminal negatif masukan inverter.

Pada pengoperasian panel PV yang perlu dilakukan adalah urutan memasukkan kontak sisi tegangan searah dan sisi tegangan bolak-balik, pada saat awal dioperasikan maka urutan dimulai dari sisi kontak pemutus panel surya baru dilanjutkan pada sisi keluaran inverter, sedangkan pada waktu akan berhenti operasi, maka pertama tama pelepasan kontak dilakukan pada sisi beban atau jaringan, baru kemudian pada sisi pemutus panel surya. Pemantauan harus selalu dilakukan mengingat bahwa daya yang dihasilkan bergantung kepada kondisi penyinaran, bila penyinaran berkurang, maka daya yang dihasilkan panel surya juga berkurang.

Pada pemeliharaan panel surya, hal pokok yang perlu dilakukan adalah menjamin kebersihan permukaan modul, karena daya yang dihasilkan tergantung dari kondisi kebersihan permukaan modul. Oleh sebab itu pemeliharaan kebersihan permukaan modul surya menjadi salah satu aktifitas pemeliharaan pokok pada pengoperasian panel surya.

Instalasi panel PV adalah instalasi kelistrikan oleh sebab itu persyaratan instalasi harus dipenuhi pada sistem tegangan dc dan sistem tegangan ac yang ada pada instalasi tersebut. Instalasi mencakup pengawatan, kontaktor, pengaman dan pembumian yang diperiksa sebelum instalasi dioperasikan.

\subsection{Regulasi penggunaan panel surya fotovoltaik}

Dari sisi perundang-undangan, pemasangan dan pengoperasian panel surya yang terhubung ke jaringan dan sekaligus sebagai konsumen PLN, mengacu kepada ketentuan yang dikeluarkan oleh Kementrian Energi dan Sumber Daya Mineral (ESDM). Pada Peraturan Menteri ESDM No.19 tahun 2016 terdapat hal-hal terkait pembelian tenaga listrik dari pembangkit listrik tenaga surya fotovoltaik oleh PLN. Selanjutnya Permen ESDM No. 50 tahun 2017 dapat diketahui tentang pemanfaatan energi terbarukan untuk penyediaan tenaga listrik. Pada tahun 2018, dikeluarkan Permen ESDM No.49 tentang penggunaan sistem pembangkit listrik tenaga surya atap oleh konsumen PT PLN terkait batasan kapasitas dan proses yang harus dilalui untuk mendapat persetujuan pemasangan instalasi panel surya sebagai pembangkit listrik.

Pada permen ESDM No.13 tahun 2019 yang merupakan perubahan dari Permen ESDM No.48 tahun 2018, dalam Peraturan Mtenteri ini, ditegaskan bahwa setiap PLTS Atap wajib memiliki SLO 
atau Sertifikat Layak Operasi yang dikeluarkan oleh Lembaga Inspeksi Teknik (LIT) yang terakreditasi.

\section{PEMBAHASAN}

Pada penyampaian materi sosialisasi dan peragaan, dalam hal ini dibagi menjadi empat bagian yaitu :

- Pengenalan Institut Teknologi PLN

- Konversi energi dan modul surya, operasi, pemeliharaan dan regulasi

- Instalasi sistem panel surya

- Peragaan sistem panel surya

\subsection{Pengenalan Institut Teknologi PLN}

Para peserta diberikan penjelasan mengenai perkembangan IT PLN sejak bernama STT-YPLN di tahun 1998, sampai dengan STT-PLN dan dengan perubahan nama saat ini menjadi Institut Teknologi PLN.

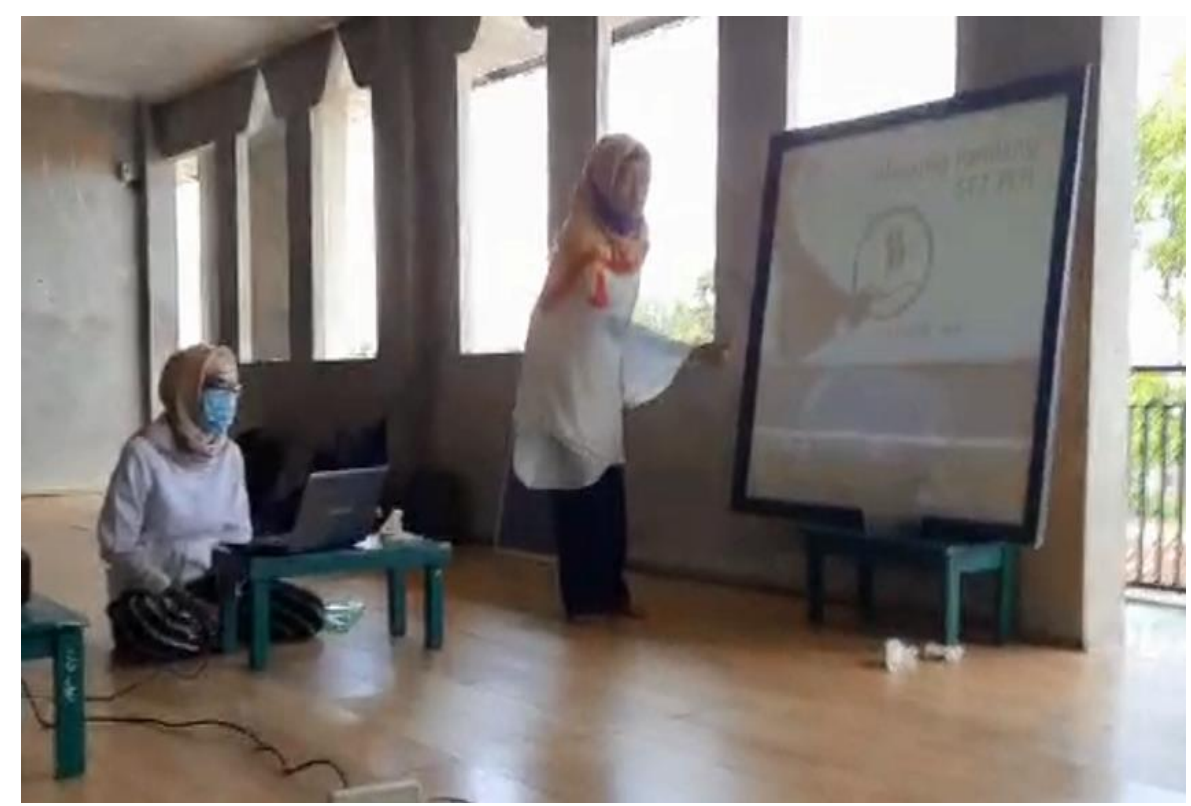

Gambar 1. Penjelasan selayang pandang IT PLN

Penjelasan juga disampaikan tentang civitas academika, terkait dosen, karyawan dan mahasiswa yang saat ini berjumlah sekitar 3000 mahasiswa. Selain fasilitas kependidikan, perpustakaan dan laboratorium juga terdapat kerjasama dengan beberapa mitra dan pemberian beasiswa bagi mahasiswa yang berprestasi.

Berbeda dengan lulusan perguruan tinggi lain, yang dapat mengikuti test di PLN atau anak perusahaan PLN setelah lulus dari pendidikannya, mahasiswa IT PLN diberikan kesempatan lebih besar atau privillage dapat mengikuti test sebagai pegawai PLN atau anak perusahaan PLN setelah semester 4 bagi tingkat D3 atau semester 6 bagi tingkat S1 dengan ketentuan IPK minimal 3.

\subsection{Konversi energi surya , modul surya, operasi dan pemeliharaan}

Salah satu bentuk konversi energi adalah dari penyinaran matahari menjadi energi listrik melalui sel surya fotovoltaik yang setiap selnya menghasilkan tegangan listrik searah 0,58 volt. 
Sebuah modul surya tersusun dari beberapa sel surya yang dihubungkan secara seri, dengan demikian sebuah modul dengan 72 sel surya, maka modul tersebut pada kondisi hubung terbuka menghasilkan tegangan searah sebesar 42 volt. Penyinaran atau iradiasi matahari berpengaruh kepada arus yang dihasilkan sel surya atau daya yang dihasilkan modul surya. Semakin besar iradiasi dalam satuan $\mathrm{W} / \mathrm{m}^{2}$, maka semakin besar daya yang dihasilkan modul. Posisi modul terhadap arah penyinaran dengan efek terbesar pada modul adalah ketika posisinya tegak lurus terhadap arah penyinaran. Penyinaran matahari dalam satu hari bervariasi mulai jam 6.30 dan bertambah besar semakin siang, selanjutnya mencapai puncak sekitar 2 jam antara jam 11 s/d jam 13, selanjutnya penyinaran berkurang dan berakhir pada jam sekitar 17.30. Apabila hari cerah, maka penyinaran berbentuk seperti sebuah bukit, demikian pula daya yang dihasilkan mengikuti bentuk kurva penyinaran yang terjadi. Bila terjadi awan lewat atau penyinaran terhalang, maka daya yang dihasilkan berkurang bahkan bisa sama sekali tidak ada daya yang dihasilkan.

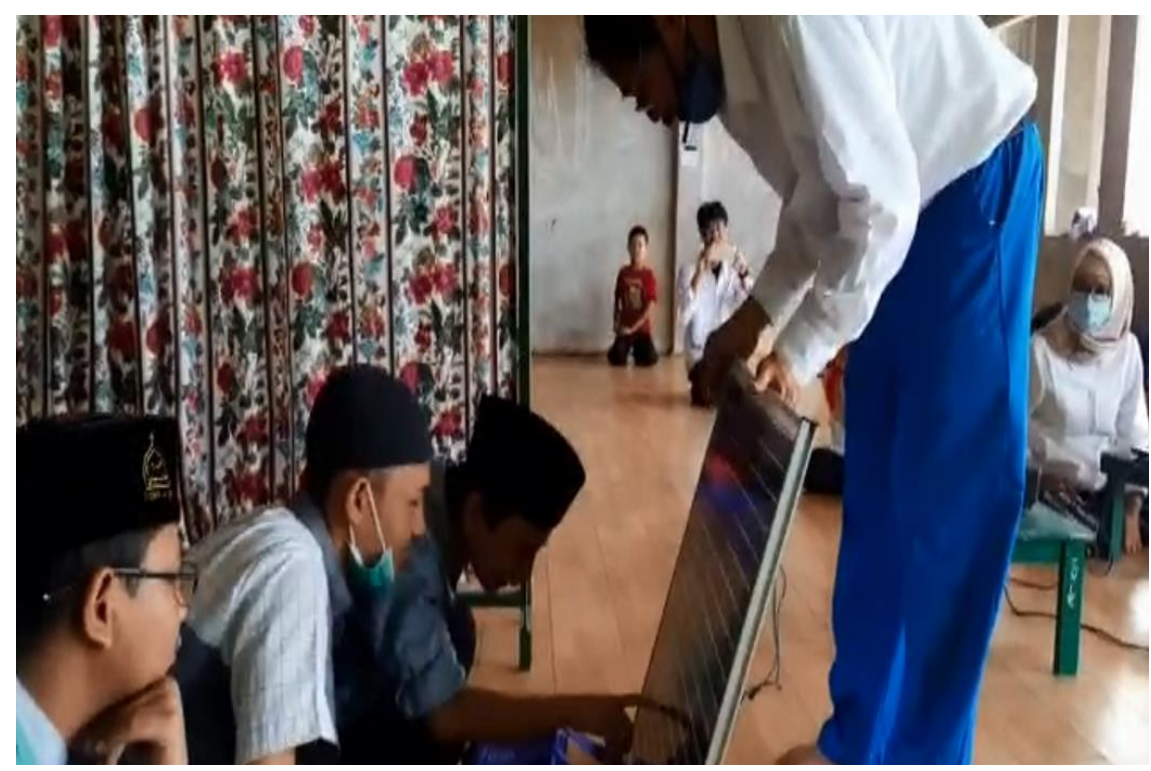

Gambar 2. Para peserta memperhatikan sel surya pada modul

Pada operasi panel surya yang tersusun dari beberapa modul atau banyak modul, maka ada konfigurasi terkait sistem panel surya dan inverter yang bisa digunakan. Titik operasi modul dengan daya maksimal adalah titik operasi kerja yang diharapkan. Titik operasi ini disebutkan pada spesifikasi sebuah modul dengan notasi Vpm sebagai tegangan pada daya maksimum dan Ipm sebagai arus pada daya maksimum. Daya maksimum sendiri merupakan spesifikasi kapasitas dari modul tersebut. Sebuah modul $50 \mathrm{Wp}$, artinya pada kondisi Standard Test Condition (STC, dengan suhu modul $25^{\circ} \mathrm{C}$, Iradiasi $1000 \mathrm{~W} / \mathrm{m}^{2}$, AM ratio 1,5), daya yang dihasilkan modul tersebut adalah $50 \mathrm{~W}$.

Performa modul tetap terjaga selama kebersihan permukaan modul juga terjaga, oleh sebab itu pemeliharaan kebersihan permukaan modul adalah syarat penting untuk mempertahankan daya keluaran dari modul dapat maksimal.

Pemantauan terhadap daya keluaran adalah merupakan hal pokok pada pengoperasian panel surya. Dengan pemantauan, maka selain mengetahui performa panel surya, juga secara tidak langsung memantau kondisi sistem panel surya. Bila sudah beroperasi lama, sementara itu diketahui kondisi penyinaran sama dengan kondisi awal operasi, tetapi daya keluaran berkurang secara signifikan, maka hal ini dapat terjadi ada indikasi permasalahan pada beberapa bagian dari sistem 
panel surya. Bila tidak di modul, masalah dapat terjadi pada inverter atau di terminasi, kontak atau di kawat penghubung.

\subsection{Instalasi sistem panel surya}

Pada instalasi sistem panel surya secara umum terdiri modul surya, inverter, kontak pemutus tegangan searah, kontak pemutus tegangan bolak-balik dan beban serta sarana pengukuran.

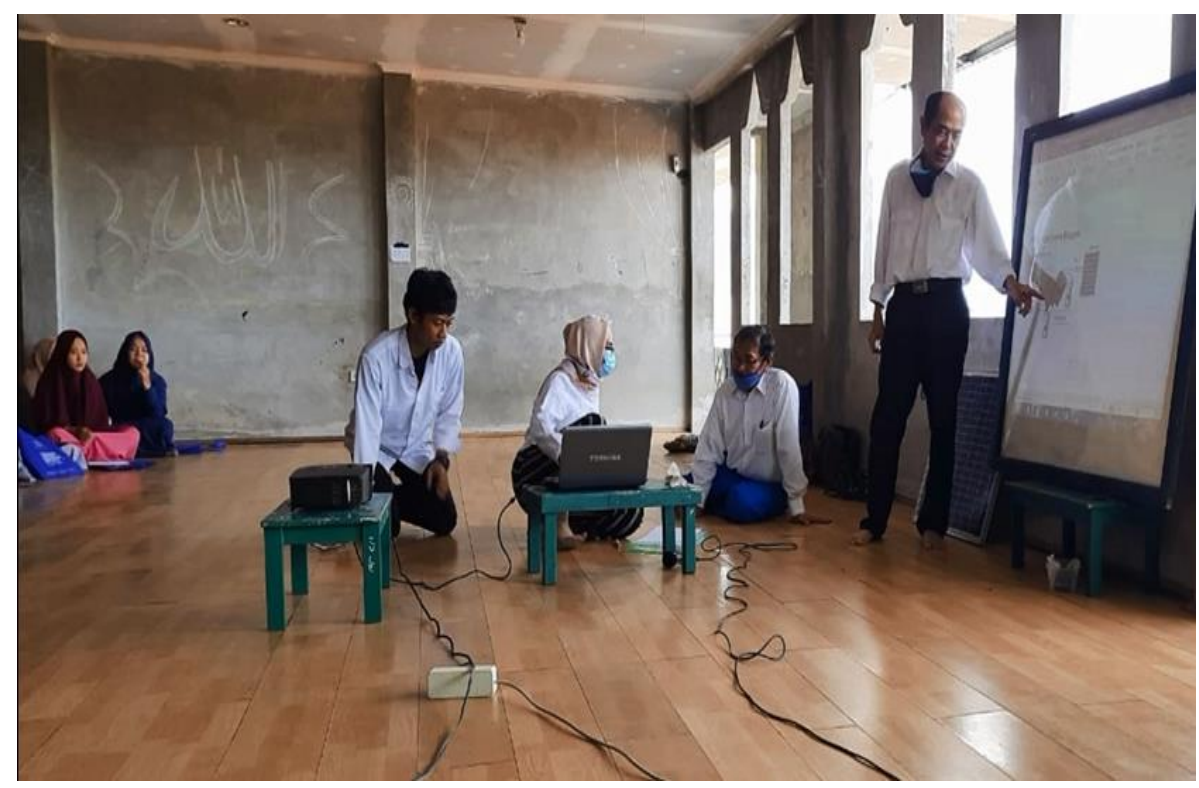

Gambar 3. Penyampaian materi instalasi sistem panel surya

Tenaga listrik yang dihasilkan oleh modul surya adalah tegangan searah yang perlu diubah menjadi tegangan bolak-balik oleh perangkat yang disebut Inverter. Inverter bekerja dengan switching tegangan searah sehingga terpotong menjadi gelombang segiempat yang diperhalus dengan filter menjadi tegangan bolak-balik sinusoidal.

Pada setiap instalasi kelistrikan termasuk instalasi sistem panel surya, penghubung antara modul surya dengan inverter dan antara inverter dengan beban menggunakan kawat penghubung berisolasi. Juga antara setiap bagian tersebut terdapat perangkat pemutus rangkaian untuk memisahkan setiap bagian dari sistem panel surya. Penghubung setiap bagian dalam hal ini harus menggunakan kabel yang ukuran penghantarnya memenuhi ketentuan pada instalasi yaitu mampu untuk menghantarkan arus kerja maksimum yang mungkin melalui penghantar tersebut. Mengenai kabel menjadi penting untuk diperhatikan, karena semakin panjang kabel yang digunakan, bisa terjadi kerugian daya yang semakin besar bila ukuran kawat penghantar kurang sesuai untuk kapasitas yang dibutuhkan. Dalam hal ini semakin besar ukuran penampang kawat penghantar yang digunakan, maka semakin kecil hambatan atau tahanan listrik yang ada pada kawat penghantar tersebut.

\subsection{Peragaan sistem panel surya}

Pada session peragaan dalam hal ini dibagi menjadi tiga tahap, yaitu pemasangan atau setup modul surya, penjelasan elemen sistem panel surya serta pengawatan dan terakhir adalah pengoperasian sistem panel surya. 


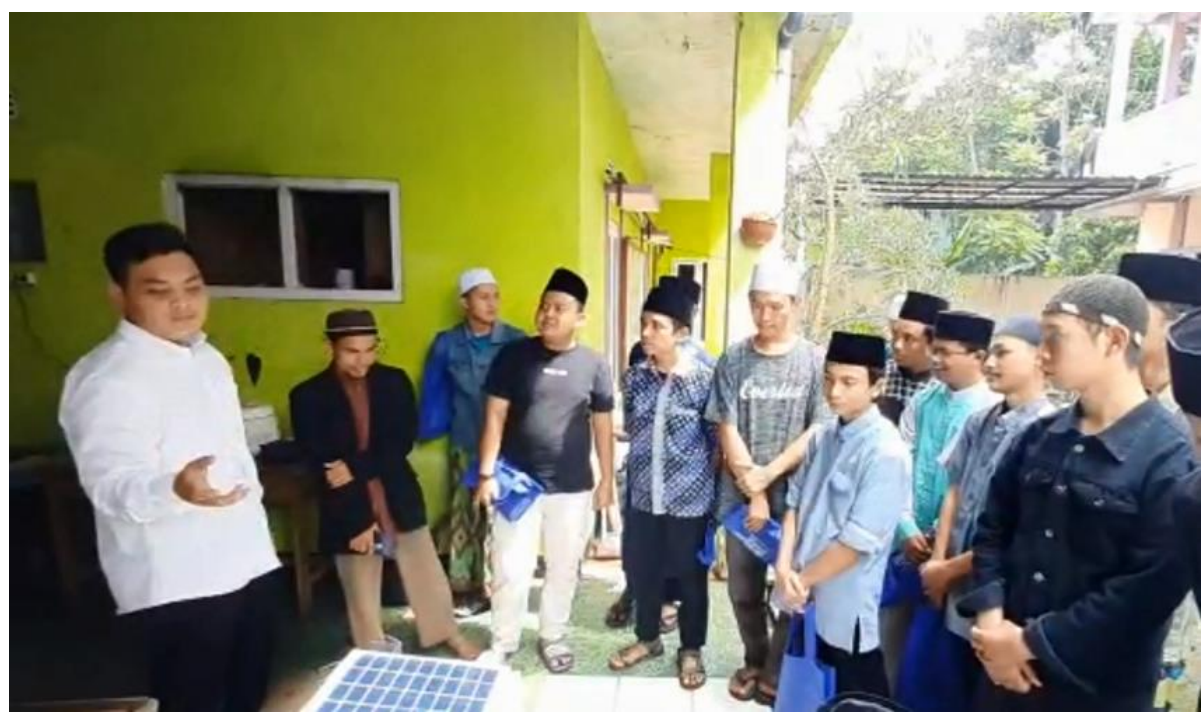

Gambar 4. Peragaan bagaimana memasang modul pada sistem panel surya

Posisi modul surya terhadap arah penyinaran menjadi penting pada saat modul pertama kali dipasang. Oleh sebab itu pada bagian ini, para peserta dibekali dengan pengetahuan yang cukup untuk bisa memasang modul agar bisa didapat hasil yang maksimal.

Pada peragaan setiap bagian dari sistem panel surya ditunjukkan secara nyata yang disebut inverter terkait kapasitas yang digunakan dan terminal yang ada pada inverter. Pada inverter, terdapat terminal sisi tegangan searah dan terminal sisi tegangan bolak-balik, yang tidak dapat ditukar atau diganti fungsinya. Pada sisi beban digunakan lampu dua buah dengan masing-masing berdaya $5 \mathrm{~W}$, tegangan $220 \mathrm{~V}$. Pada peragaan pengawatan, kepada para peserta diperlihatkan bagaimana melakukan pengawatan yang baik dengan penggunaan konektor pada ujung kawat yang dihubungkan ke terminal inverter. Penggunaan konektor ditujukan untuk mendapatkan koneksi yang baik, sehingga praktis tidak mengakibatkan kerugian energi listrik yang dihasilkan dari penyinaran matahari. Untuk memberikan pengetahuan praktis, para peserta juga diberikan kesempatan untuk melakukan pengukuran tegangan pada sisi keluaran modul dan pada keluaran inverter.

\section{KESIMPULAN}

Dari kegiatan Pengabdian kepada Masyarakat di Pondok Pesantren Khoiru Ummah dapat disimpulkan sebagai berikut :

- Peserta yang merupakan siswa di Pondok Pesantren Khoiru Ummah telah mengikuti dari awal sampai akhir acara sosialisasi ini dengan penuh antusias, yang mengindikasikan tercapainya target kegiatan ini.

- Materi sosialisasi tentang pemasangan, pengoperasian dan pemeliharaan panel surya mendapatkan tanggapan yang positif dari peserta sosialisasi dengan banyaknya peserta yang aktif bertanya jawab dari materi yang disampaikan. Hal ini mengindikasikan bahwa yang disampaikan sudah tepat untuk memenuhi kebutuhan terhadap pemahaman pengetahuan konversi energi, energi terbarukan dan sistem panel surya.

- Sosialisasi ini membawa dampak dan manfaat selain memahami hal teknis juga mengetahui perundangan secara umum dari instalasi pembangkit listrik tenaga surya. 


\section{SARAN}

Sebagai kelanjutan dari program kegiatan Pengabdian kepada Masyarakat, pada kesempatan yang mendatang sebaiknya materi sosialisasi dilanjutkan dengan materi perancangan instalasi panel surya untuk suatu komunitas.

\section{UCAPAN TERIMA KASIH}

Sebagai ungkapan rasa syukur dengan selesainya program Pengabdian kepada Masyarakat di Pondok Pesantren Khoiru Ummah, Sumedang, dengan ini tim PkM mengucapkan banyak terima kasih kepada LPPM Institut Teknologi PLN yang telah memberikan kesempatan dan sarana untuk melaksanakan program ini dari awal sampai akhir pelaksanaan program.

\section{DAFTAR PUSTAKA}

[1] A. H. A. Alwaeli and H. F. Mahdi, "Standalone PV systems for rural areas in Sabah , Malaysia: Review and case study application," January, 2017.

[2] "Peraturan Menteri ESDM RI No.12 tahun 2017 tentang pemanfaatan sumber energi terbarukan untuk penyediaan tenaga listrik," 2017.

[3] "Peraturan Menteri ESDM RI No.49 tahun 2018 tentang penggunaaan Sistem Pembangkit Listrik Tenaga Surya atap bagi konsumen PT PLN (Persero)," 2018.

[4] "Peraturan Menteri ESDM RI No.13 tahun 2019 tentang Aturan Perubahan penggunaaan Sistem Pembangkit Listrik Tenaga Surya atap bagi konsumen PT PLN (Persero)," 2019.

[5] "Peraturan Menteri ESDM RI No.19 tahun 2016 tentang pembelian tenaga listrik pembangkit listrik tenaga surya fotovoltaik oleh PT PLN(Persero)," 2016.

[6] N. M. Kumar, M. S. P. Subathra, and J. E. Moses, "Small Scale Rooftop Solar PV Systems for Rural Electrification in India,” 2018 4th Int. Conf. Electr. Energy Syst., no. February, pp. 611615, 2018.

[7] A. S. G. E Diaz Dorado, "Influence of shadow in photovoltaic systems with different configurations of by pass diodes," Int. Symp. Power Electron. Electr. Drive, Autom. Motion, pp. 5440343-5440344, 2010. 